\title{
Vivienda tradicional en Ensenada, Baja California México. Adecuación ambiental
}

\section{Traditional housing in Ensenada, Baja California Mexico. Environmental adaptation}

DOI: $10.46932 / \mathrm{sfjdv2n2-154}$

Received in: March 1st, 2021

Accepted in: May 30th, 2021

\section{Claudia Marcela Calderón Aguilera}

Doctor en Arquitectura. Universidad Autónoma de Baja California. Facultad de Ingeniería Arquitectura y Diseño. Address: Carretera Transpeninsular Ensenada-Tijuana 3917, Colonia Playitas, Ensenada,

Baja California México., C.P. 22860,

E-mail. claudiacalderon@uabc.edu.mx

\section{Cuauhtémoc Robles Cairo}

Maestro en Arquitectura. Universidad Autónoma de Baja California. Facultad de Arquitectura y Diseño. Mexicali México.

E-mail: cuauhtemoc@uabc.edu.mx

\section{RESUMEN}

Hace 135 años se fundó oficialmente en el noroccidente mexicano la ciudad y puerto de Ensenada en el estado de Baja California México. Su clima es mediterráneo y su historia, conformación y desarrollo urbano-arquitectónico fue disímil respecto a otras ciudades del país. Algunos de los factores determinantes para ello fueron: los geográficos, los económicos y los políticos, estos últimos reflejados en las inversiones extranjeras realizadas en el país producto de las concesiones otorgadas sobre territorio mexicano en las últimas décadas del siglo XIX y las primeras del siglo XX. En consecuencia la arquitectura edificada en ese periodo es una prueba fehaciente de la influencia cultural anglosajona que vivió la ciudad. Además de ello, específicamente en la vivienda se implementaron estrategias de adecuación ambiental que respondieron a una integración al entorno y atenuador de las circunstancias climáticas, las cuales en este trabajo se identifican y analizan. Se concluye con la idea y la importancia de volver los ojos al pasado y retomar los valores que ellas contienen.

Palabras Clave: Adecuación ambiental, vivienda tradicional, Ensenada México.

\begin{abstract}
The city and port of Ensenada located in the northwest of Mexico, was officially founded 135 years ago (1882). Its climate is considered Mediterranean, its history, conformation and urban-architectonic development contrasts in comparison with most cities in the country. Some of the determining factors leading to these differences were: its geographical location, economic and political (isolated from most of the develop part of the country and its capital). These differences are mainly visible due to the foreign investments made during the last decades of the XIX century and the first of the XX, as a result of the concessions granted by Mexican government. Architecture from this time has a strong cultural AngloSaxon influence, more specifically, traditional dwelling from the epoch included climate specific adaptations, which are identified and analysed in this work. It is concluded that it is of paramount importance to look back and learn from the value that is preserved in these dwellings.
\end{abstract}

Key words: climate adaptation strategies, traditional dwelling, Ensenada México. 


\section{GEOGRAFÍA Y CLIMA.}

En el estado de Baja California dentro de la costa noroeste de México se localiza la ciudad y puerto de Ensenada. Sus coordenadas geográficas la localizan a los $31^{\circ} 53^{\prime}$ latitud norte y a los $116^{\circ} 37^{\prime}$ de longitud oeste. El centro de población es un asentamiento costero, delimitado al oeste por el océano Pacífico, en el cual se ubica la Bahía de Todos Santos de Ensenada que tiene 14.5 kilómetros de longitud por 11.3 kilómetros de ancho. Respecto a la superficie total del país, el municipio de Ensenada representa el $2.6 \%$.

Su macrobioclima es considerado como Mediterráneo con carácter extratropical con seis meses de invierno frío y lluvias moderadas, y un verano seco y caliente. Su temperatura promedio media anual es de $17.2^{\circ} \mathrm{C}$, humedad relativa media de $71 \%$ y precipitación anual promedio de $260.7 \mathrm{~mm}$. Los vientos dominantes provienen del Noroeste. A la ciudad sólo la cruzan pequeños arroyos, los cuales durante gran parte del año se encuentran secos y sólo durante las lluvias invernales llevan escurrimientos

Contiene un área urbana de poco más de $61 \mathrm{~km}^{2}$. En general la ciudad es plana y extendida, las partes más altas están localizadas al norte y noroeste de la bahía. Actualmente el $42 \%$ de la zona urbana de Ensenada es habitacional.

Fig. 1 Localización geográfica

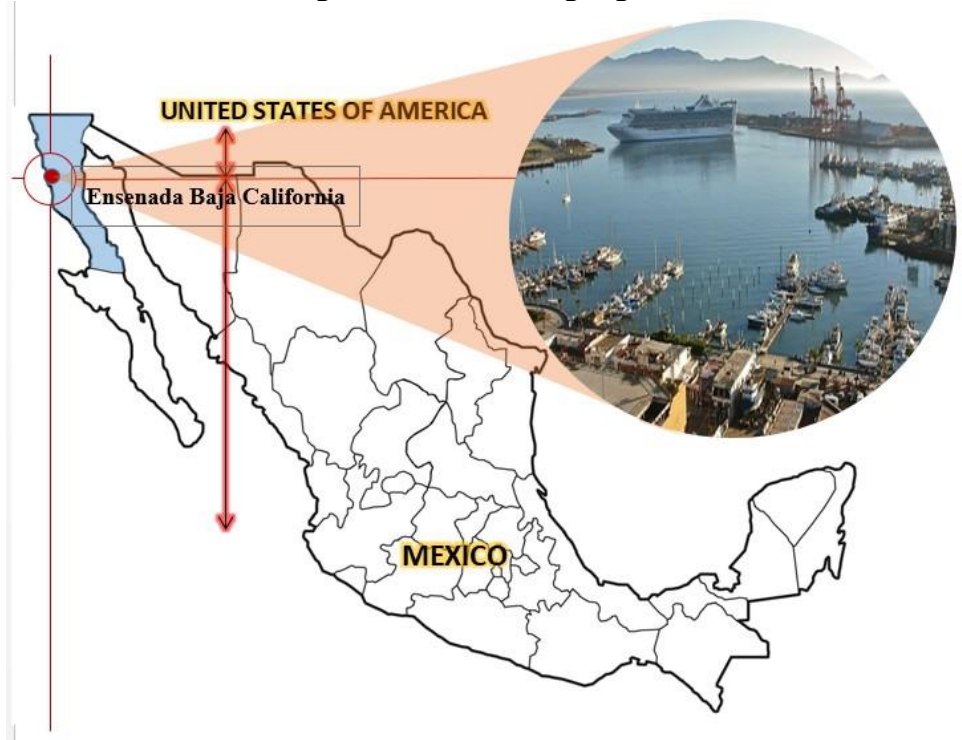

Fuente. Autores 2019

\section{CONFORMACIÓN DE LA CIUDAD}

El primer propietario fue el comandante de la frontera de la Baja California José Manuel Ruiz, y data del año 1804; la propiedad tenía una extensión de 3,494 hectáreas. El segundo propietario fue el señor Gastelum, mismo que en el año de 1880 lotificó una parte de la propiedad y con ese plano inició la venta de lotes. Así quedó plasmada la primera traza urbana de la ciudad, la cual se desarrolló en una retícula 
ortogonal regular dividida en manzanas cuadradas de 100 metros por lado y desviadas $45^{\circ}$ respecto al norte geográfico, con calles de $25 \mathrm{~m}$ de ancho, y la lotificación resultante fueron propiedades de 25 por 50 metros (Calderón, C. y Geffroy, B. 2001).

En la primera traza urbana se puede observar con claridad la consideración que tuvieron los pobladores originales respecto al clima al ubicar el desarrollo de la traza urbana resguardada por el cerro el vigía, -localizado en la entrada del centro de población-, mismo que los protegería de los fuertes vientos de mar a tierra.

El 15 de mayo de 1882 Ensenada adquiere la categoría de cabecera del Partido Norte de la Baja California y con ello ésta es la fecha oficial de la fundación de la ciudad. En 1884 el gobierno mexicano otorgó concesiones sobre tierras mexicanas a compañías deslindadoras extranjeras. De 1884 a 1889 se instaló en la ciudad, la International Company of Mexico y de 1889 a 1917 la Mexican Land and Colonization Co. Ltd., o Compañía Mexicana de Terrenos y Colonización, conocida como la Compañía Inglesa. Los negocios e inversiones de ésta última no se desarrollaron como se esperaba y por ello incumplieron con lo estipulado en el convenio de concesión, razón por la cual en 1917 la Compañía Inglesa fue intervenida y su concesión cancelada. A partir de entonces son tres los factores que cambian el rumbo y el desarrollo de la ciudad: primero, el cierre de la Compañías deslindadoras en 1917; segundo, el cambio de sede política y administrativa de Ensenada a la ciudad de Mexicali, misma que hace frontera con el estado de California de la Unión Americana en 1915; y tercero por la puesta en vigor de la Ley seca en Estados Unidos a partir de 1919 (Calderón y Geffroy, 2001).

Fig. 2 Inmueble de la International Company of Mexico en Ensenada Baja California México

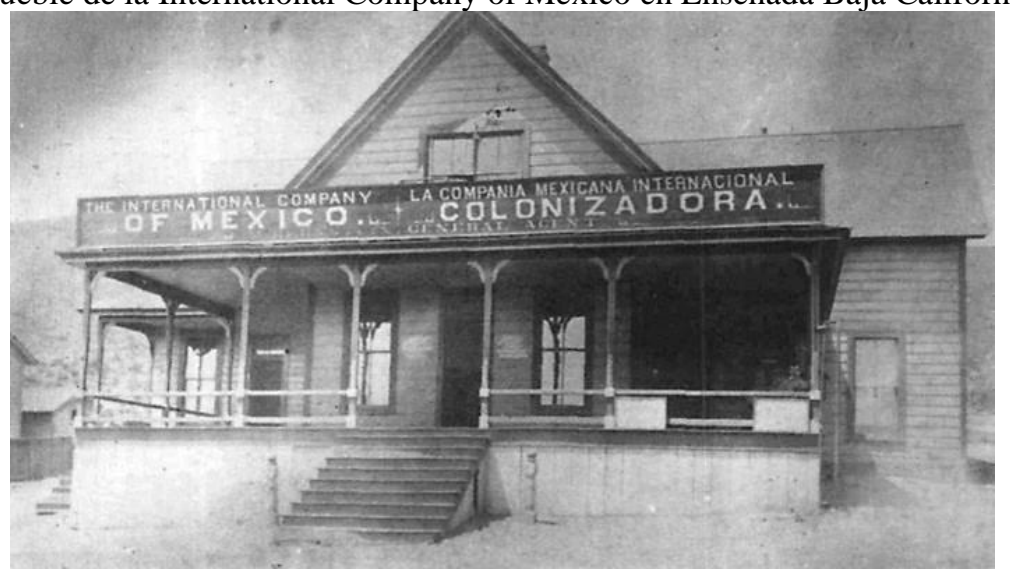

Fuente. Dominio público

En el año de 1886 la compañía deslindadora realizó un segundo plano de la ciudad que mostró las grandes perspectivas de desarrollo urbano que tenían las inversiones extranjeras y en el cual quedó plasmado la segunda traza urbana de la ciudad, misma que fue desviada poco más de 25 grados respecto al norte geográfico. Es así como al inicio del siglo XX Ensenada plasmó en su territorio las dos trazas 
urbanas fundamentales que la conformaron por los primeros 50 años de existencia. El nacimiento, desarrollo y conformación de la ciudad y puerto de Ensenada iniciado en las últimas décadas del siglo XIX y las primeras del siglo XX vino acompañado de la vivienda necesaria para ello.

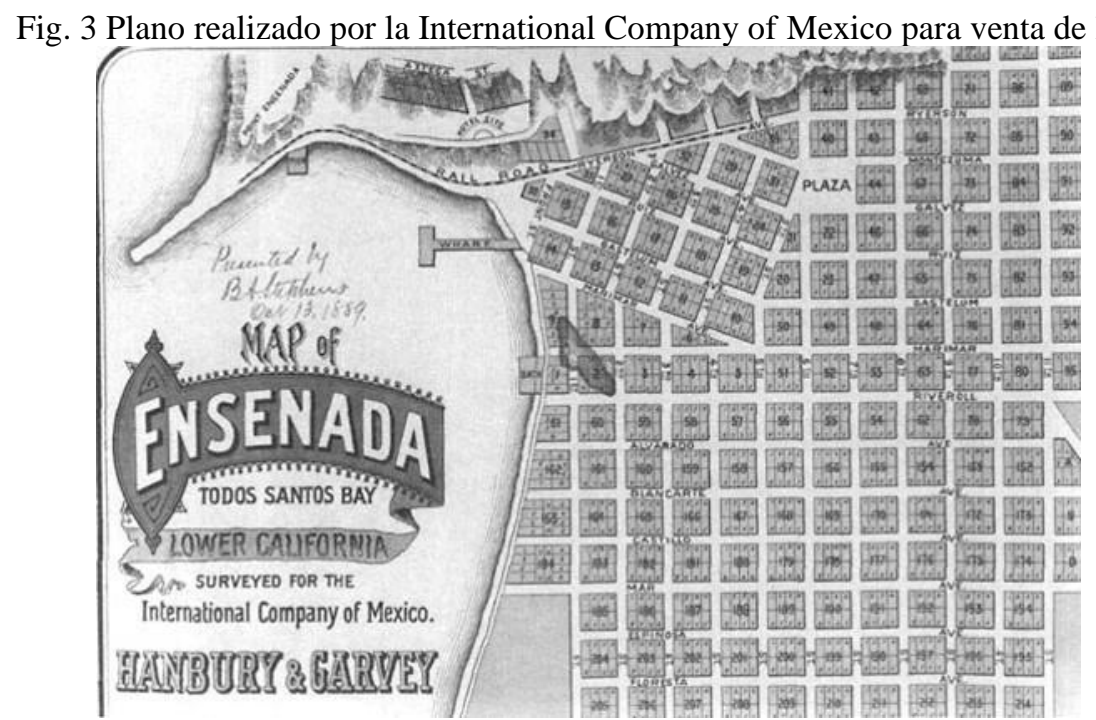

Fuente. The Journal of San Diego History Map of Ensenada, surveyed for the International Company of Mexico, 1889. courtesy Natural History Museum

\section{VIVIENDA TRADICIONAL}

En la zona centro de Ensenada el panorama de las calles y manzanas tiene tendencia a la horizontalidad, la gran mayoría de las viviendas son de un nivel, son escasas las viviendas en uno y medio nivel y las de dos niveles son prácticamente inexistentes.

El tipo de vivienda que reconocemos como tradicional es aquella que fue importada por las compañías colonizadoras que tuvieron sede en la ciudad. De hecho, estas viviendas de madera de pino rojo (redwood), son las que más identifica la ciudadanía con este periodo de Ensenada, quizá por lo inusual de este tipo específico de construcción en México. Fueron importadas en su mayoría del vecino estado de California, al suroeste de Estados Unidos, y la madera provenía de la región de Corte Madera, los condados de Mendocino, Humboldt y Del Norte. Llegaron a Ensenada por vía marítima o terrestre. (Calderón y Geffroy, 2001).

Autores como López Morales (1993) en su libro de Arquitectura vernácula en México mencionan que:

"La influencia y presencia de la cultura novohispana en el norte se hace patente no sólo en la toponimia, sino también en la construcción y en la arquitectura, por modesta que sea. La presencia mexicana llega hasta alli donde exista una casa hecha con adobe. El pueblo angloamericano marca la suya con construcciones de madera, aun compartiendo el mismo medio geográfico. Las fronteras se registran culturalmente por medio de la arquitectura, de acuerdo con las soluciones que propone según su carácter constructivo. Las misiones, los presidios, los ranchos y las haciendas hechos con 
anchos muros de adobe, son instituciones fronterizas en la región norte de la Nueva España. El reflujo y repliegue de nuestro límite con los Estados Unidos se nota por la presencia de muchas construcciones de madera en casi toda la franja limítrofe del norte".

Estas viviendas de madera, están realizadas con una tecnología constructiva a base de marcos de madera, a la cual en inglés, se le denominó balloon frame, es un sistema constructivo basado en una estructura tipo jaula de bastidores con pies derechos y viguetas de madera de 5.08 centímetros X 10.16 centímetros@40 centímetros, sujetadas por clavos, “...las paredes de este tipo de construcción eran aisladas con un tejido de latilla y emplasto de estuco entre la pared exterior y la interior. Este tipo de emplasto servía como aislante para regular la temperatura en las habitaciones. Los clavos con que fueron unidas las maderas son de cabeza cuadrada" (La vida en Ensenada, 1995). El muro era finalizado a base de un emplaste de estuco o con tablones pintados y colocados en sentido horizontal o vertical.

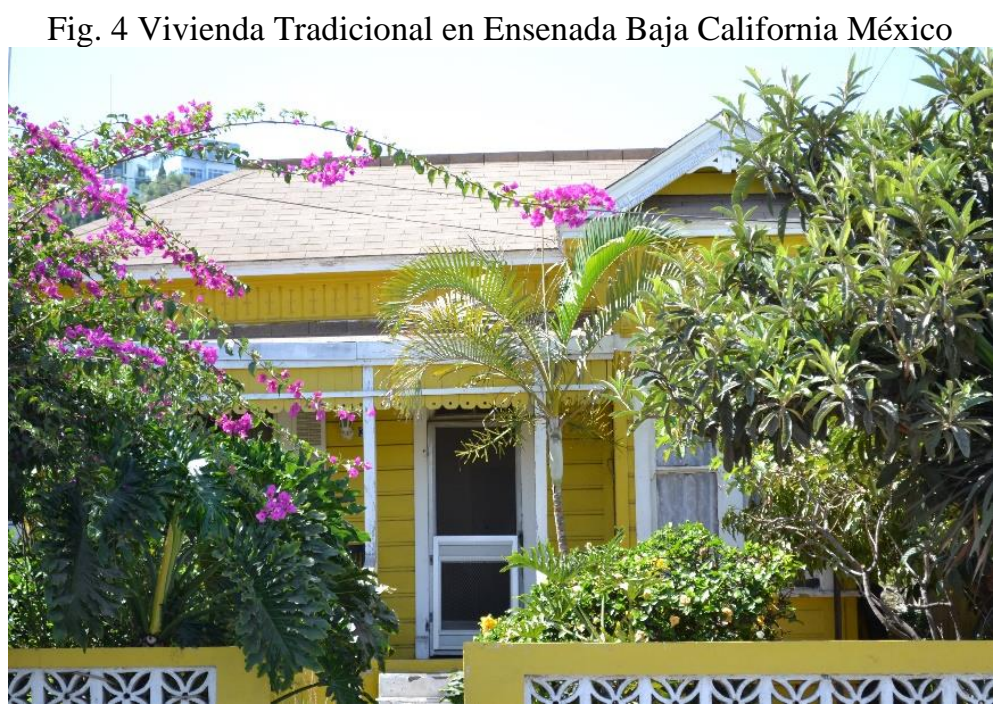

Fuente. Autores 2020

\section{ESTRATEGIAS DE ADECUACIÓN AMBIENTAL}

A partir de las ideas que se han recapitulado líneas arriba se puede entender que en las viviendas prefabricadas se expresó el fenómeno multicultural en la localidad. En ellas se reflejó una forma de vida simple, informal y moderna. Su periodo de proliferación en California y en la Baja California, coincidió con el arribo masivo de inmigrantes provenientes de la costa este estadounidense, principalmente personas jóvenes y parejas atraídas por oportunidades de trabajo, el moderado costo de las propiedades y sobre todo por las bondades del tibio clima californiano. Los recién llegados encontraron en esta tipología de vivienda una casa casi lista, ready made, para ordenarse por correo, erigirse y habitarse.

A continuación se delinean las estrategias de adecuación ambiental que conjunta la vivienda tradicional a partir de un análisis de sus componentes arquitectónicos: 
- La vivienda se edifica en un solo nivel y se desplanta al frente del lote sin llegar al límite de propiedad, dejando circulaciones en las áreas laterales y la mayor disposición de terreno libre en la parte posterior. Esto se interpreta de diversas maneras: primero como un deseo de privacidad e individualizar y por lo tanto aislar la propiedad; segundo por razones de protección contra posibles incendios dado que la madera es altamente inflamable; y tercero por tratar de reafirmar a través del aislamiento su afinidad suburbana o rural.

- La organización funcional-espacial se resuelve mediante la diferenciación de cuatro áreas: la pública en correspondencia al exterior; semipública al frente y a través del pórtico; área semiprivada que contiene a la sala, al comedor y a la cocina y finalmente las habitaciones de uso privado.

- $\quad$ El diseño arquitectónico es compacto con lo cual se optimizan las condiciones ambientales de iluminación y temperatura mediante el uso de ventanas y aleros en las fachadas y el uso del pórtico frontal, siendo estos dispositivos, sencillos y eficaces.

- $\quad$ El uso de pórticos con diferentes dimensiones, profundidades y formas, que además de ser un espacio de convivencia familiar y de transición entre el exterior y el interior, funciona como un sistema pasivo de climatización. Tiene una clara función refrigerante mediante la proyección de sombra sobre la fachada con más incidencia de la radiación solar, lo que trae como consecuencia que los espacios interiores sean más frescos y por lo tanto más confortables respecto a su temperatura.

- $\quad$ El uso de color claro en los muros exteriores. La madera que recubre la estructura de la vivienda es pintada en colores claros. Esto contribuye a la percepción de ligereza de la vivienda. La elección de colores claros tiene ventajas en relación a los colores oscuros, puesto que se refleja en mayor cantidad la radiación solar y permite un mejor aprovechamiento en lo que respecta a la iluminación natural.

- El sistema constructivo utilizado, el balloon frame, el cual tiene tres aspectos de adecuación al medio ambiente local: flexibilidad constructiva respecto a su diseño y futuras ampliaciones; flexibilidad en la estructura acorde con la zona sísmica donde se localiza Ensenada y la rapidez y la economía para su edificación.

- A las viviendas se les incorpora un sistema de aireación y protección natural, esto se logra al elevar la edificación respecto al nivel natural de terreno, las razones: la topografía de la ciudad es plana y se debía evitar el riesgo de posible inundación en las lluvias invernales; el terreno es de gran dureza; y se favorece el paso libre de ventilación por debajo de la edificación, pero se desfavorece el enfriamiento conductivo que provoca el piso sobre el suelo. 
- Los muros realizados con materiales ligeros como la madera, son de baja inercia térmica y por lo tanto poco conductores del calor.

- Se utilizan aleros para provocar sombra y a todo lo largo de las fachadas para la protección solar en verano y permitir la entrada de sol en invierno.

- La cubierta es inclinada y funciona de dos maneras: como captadora de calor que absorbe la energía y la acumulan para posteriormente cederla y para el desalojo de las aguas pluviales.

- $\quad$ El ático ventilado a partir de la cubierta de madera al exterior y cielo raso al interior; se instalan rejillas provocando túneles de viento con lo que se reduce la ganancia térmica diurna hacia el interior; Además, se genera el enfriamiento radiativo nocturno, con lo que se pierde parte de la energía que se obtiene en el día.

- La ventilación cruzada propiciada por la conformación compacta del diseño arquitectónico.

- $\quad$ La vegetación exterior que es utilizada en variados espacios del lote, ya sea en los jardines frontales, laterales o posteriores y sumándole el uso de macetas en los pórticos. La vegetación se riega durante el verano y produce un enfriamiento del ambiente circundante a la vivienda a través de la evaporación. Lo anterior, genera la creación de microclimas cálido-húmedos en el perímetro de la edificación, reduciendo la temperatura del aire que posteriormente se utiliza para la ventilación natural de la vivienda, no solo en el espacio exterior y a través de las ventanas, sino también en el ático y el respiradero, con un aire a menor temperatura que en las zonas sin vegetación (Robles, 2009).

- Otros elementos utilizados son la chimenea, que se utiliza en el invierno y el invernadero adosado el cual funciona como un espacio de ganancia solar y por convección calienta el espacio habitable.

Fig. 5 Organización funcional y espacial de la vivienda

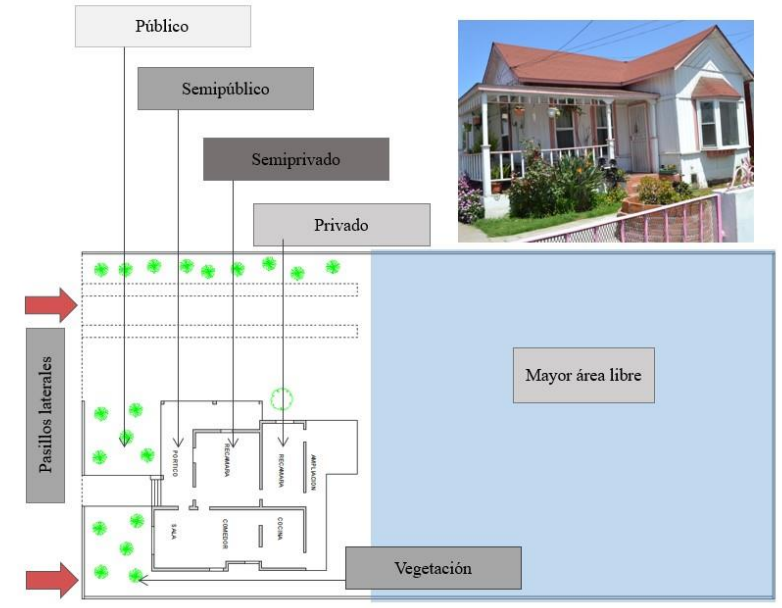

Fuente. Autores 2019 
Fig. 6 Detalle de pórtico sombreado y aleros

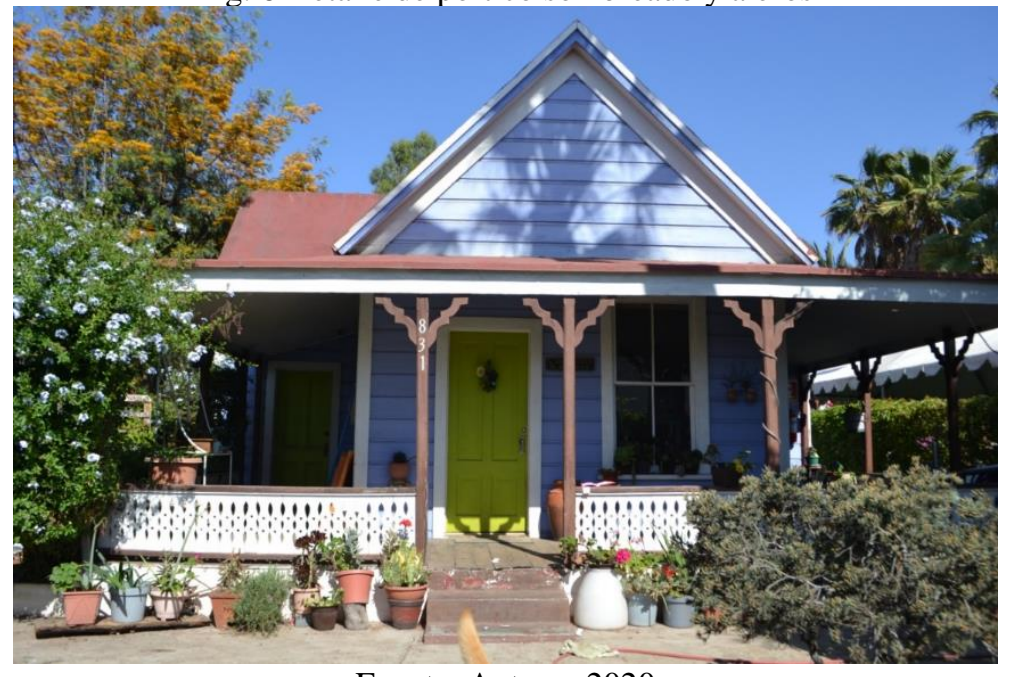

Fuente. Autores 2020

Fig. 7 Detalle de áticos ventilados

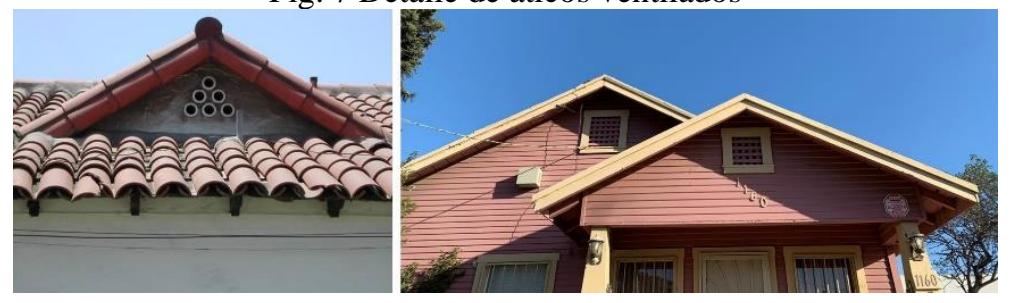

Fuente. Autores 2020

Fig. 8 Vivienda con vegetación exterior y color claro en muros

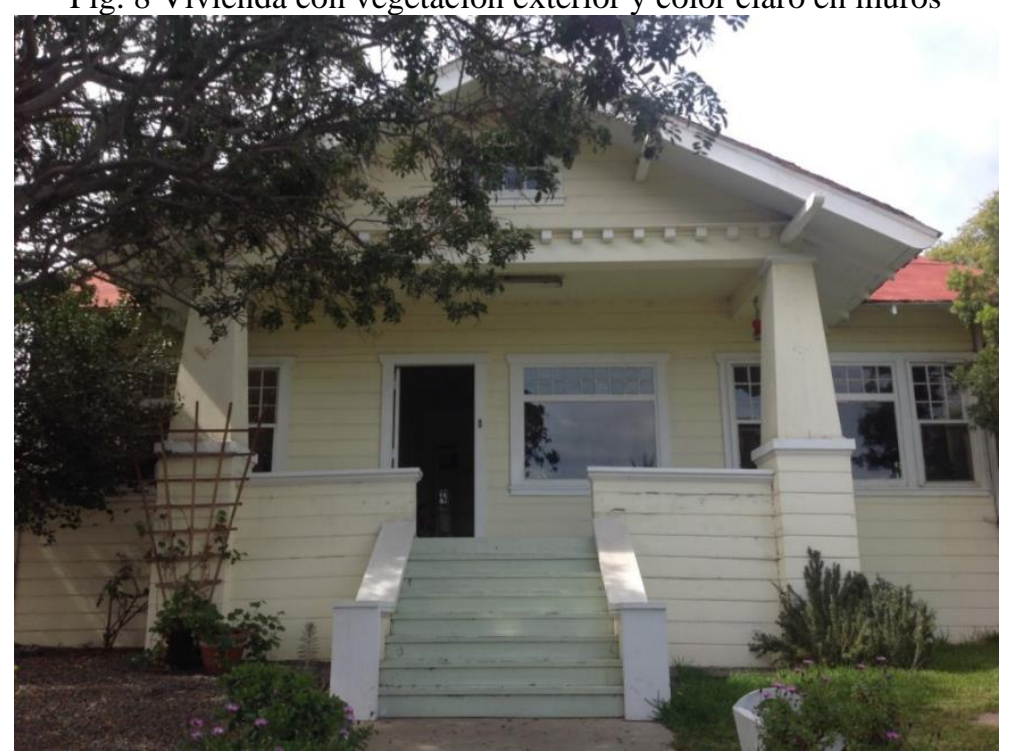

Fuente. Autores 2020

\section{REFLEXIONES FINALES}

- La vivienda tradicional de Ensenada es el resultado de diversos componentes básicos: a) la cercanía con Estados Unidos, tan solo a 100 Kilómetros de la frontera, b) su lejanía con el centro 
del país, c) La inversión de capitales extranjeros en México dentro de la frontera norte d) y las concesiones otorgadas sobre territorio mexicano a finales del siglo XIX.

- Los aspectos del clima así como la forma de vida de las sociedades, son factores importantes en la configuración del espacio arquitectónico.

- La vivienda tradicional de Ensenada Baja California México logró adaptarse al medio ambiente circundante mediante patrones arquitectónicos muy específicos con respecto a su localización geográfica, entorno y clima mediterráneo.

- Las estrategias de adaptación al clima local incrementan las condiciones de habitabilidad y confort y deben ser un referente en la producción de la vivienda contemporánea, ya que han probado su efectividad por más de un siglo.

- $\quad$ Finalmente, es en la vivienda tradicional donde se desarrolló una arquitectura que adaptó esas importaciones a las circunstancias geográficas y sociales del lugar creando formas y espacios originales que identifican a la ciudad. 


\section{REFERENCIAS}

Calderón, C., \& Geffroy, B. (2001). Un siglo de arquitectura en Ensenada. Mexicali Baja California México: Fondo Editorial del Gobierno del Estado de Baja California CONACULTA Instituto de Cultura de Baja California.

Calderón, C. (2011). Adecuación bioclimática de la Vivienda tradicional en Ensenada. 1882-1930. Mexicali Baja California México:

Giedion, S. (1965). Space, time and architecture. Harvard Univeristy Press.

_La vida en Ensenada, (1995). Revista. Agosto-Septiembre.

López, F. (1993). Arquitectura vernácula en México. Editorial Trillas. México.

Mathes, M. (1988). Baja California. Textos de su Historia. Instituto de Investigaciones Dr. José María Luis Mora, SEP, Gobierno del Estado de Baja California. México.

Padilla, A. (1999). Influencias urbanas en la región, Ensenada nuevas aportaciones para su historia. Universidad Autónoma de Baja California. México

Piñera, D. (1991). Los orígenes de Ensenada y la política nacional de colonización. Fondo Editorial Universidad Autónoma de Baja California. Mexicali Baja California México.

Robles, C. (2009). La arquitectura de Mexicali, orígenes. Universidad Autónoma de Baja California. Mexicali, México.

Rodríguez, M. (2002). Arquitectura y Clima. Universidad Autónoma Metropolitana. Atzcapozalco, México. 